\title{
O CURSO DE ENFERMAGEM DA UNIVERSIDADE ESTADUAL DE LONDRINA NA CONSTRUÇÃo de UMA NOVA PROPOSTA PEDAGógica
}

Godoy CB. O curso de enfermagem da Universidade Estadual de Londrina na construção de uma nova proposta pedagógica. Rev Latino-am Enfermagem 2002 julho-agosto; 10(4):596-603.

O artigo teve como objetivo levantar a história do Currículo de Enfermagem da Universidade Estadual de Londrina, desde a implantação do Curso, em 1972, até o currículo atual, implantado em janeiro de 2000. O estudo constituiu-se em pesquisa bibliográfica e o resultado possibilitou delinear todo o processo de mudança curricular frente à inquietação dos docentes e às exigências do mercado de trabalho. O estudo, ao fundamentar todas as mudanças curriculares, contribui para melhor compreendermos a nova proposta pedagógica, baseada na concepção crítico-social e respaldada na pedagogia problematizadora, aplicada no atual Currículo Integrado do Curso de Enfermagem, da Universidade Estadual de Londrina.

DESCRITORES: currículo, enfermagem

\section{THE NURSING PROGRAM OF THE STATE UNIVERSITY OF LONDRINA IN THE CONSTRUCTION OF A NEW EDUCATIONAL PROPOSAL}

This study aimed at outlining the history of the Nursing Curriculum of the State University of Londrina from its beginning in 1972 to the elaboration of the present Curriculum, which was implemented in January 2000. The study was based on a literature review and the results enabled us to outline the whole process of curricular changes in view of the the professors' disquiet and the demands from the work. By substantiating all the curricular changes, the study has contributed to a better understanding of the new educational proposal, which is based on the critical and social conception founded on the problem-based pedagogy applied in the current Integrated Nursing Curriculum of the State University of Londrina.

DESCRIPTORS: curriculum, nursing

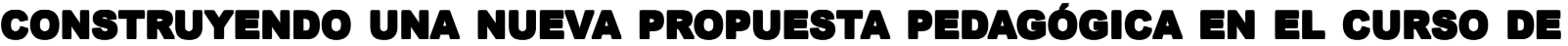 ENFERMERÍA DE LA UNIVERSIDAD ESTATAL DE LONDRINA}

El articulo tuvo como objetivo levantar la historia del Currículum de Enfermería de la Universidad Estatal de Londrina, desde la implantación del Curso, en 1972, hasta el currículum actual, implantado en enero de 2000. El estudio se constituyó en pesquisa bibliográfica y el resultado posibilitó delinear todo el proceso de cambio curricular frente a la inquietud de los docentes y a las exigencias del mercado laboral. El estudio, al fundamentar todos los cambios curriculares, contribuye para comprender mejor la nueva propuesta pedagógica aplicada en el actual Currículum Integrado del Curso de Enfermería de la Universidad Estatal de Londrina.

DESCRIPTORES: currículum, enfermería

\footnotetext{
${ }^{1}$ Universidade Estadual de Londrina, e-mail: leocris2001@aol.com
} 
O Curso de Graduação em Enfermagem, da

Universidade Estadual de Londrina, desde a sua implantação, em 1972, tem passado por sucessivas reformulações curriculares, resultantes, sempre, de amplas discussões e reflexões, orientadas pelo compromisso com a melhoria da qualidade do ensino e da prestação dos serviços de saúde à população ${ }^{(1)}$.

A primeira mudança curricular ocorreu em 1973, quando o curso, com duração de três anos, passou de sistema seriado para sistema de créditos.

Nesse período, através da Resolução n 04/72, foi aprovado o currículo mínimo para o Curso de Enfermagem, caracterizado por um ciclo básico, um tronco profissionalizante e três diferentes habilitações: Enfermagem em Saúde Pública, Obstétrica e MédicoCirúrgica. As habilitações, não obrigatórias, poderiam vir a ser cursadas pelo aluno, após o término da graduação.

A organização da proposta curricular, segundo o definido pelo Ministério da Educação, fez com que o ciclo básico passasse a consumir quase $50 \%$ da carga horária total do curso, em detrimento do tronco profissionalizante, que gerou enorme preocupação quanto às reais possibilidades do egresso, no desempenho profissional, e terminou por determinar uma segunda mudança curricular, discutida e esboçada durante o I Fórum de Debates sobre o Curso de Enfermagem da Universidade Estadual de Londrina, realizado em 1977, que estabeleceu os limites e possibilidades da alteração curricular promovida em 1980.

Nessa segunda reformulação curricular, a duração do curso foi ampliada para três anos e meio e destinou-se maior carga horária para as disciplinas profissionalizantes. Mas, apesar das alterações promovidas, permaneceu a dicotomia entre teoria e prática, em virtude da segmentação entre disciplinas teóricas e estágios.

No decorrer da década de 80 (oitenta), ocorreram mudanças na política de saúde do país. As novas demandas que se interpunham ao setor foram analisadas e discutidas na $8^{a}$ Conferência Municipal de Saúde, ocorrida em 1988. Os serviços de saúde procuravam se reorganizar e, com isso criaram-se novos mercados de trabalho para o enfermeiro.

Essa nova realidade veio fomentar uma inquietude crescente junto àqueles que atuavam no ensino de enfermagem, pois evidencia-se, então, a necessidade de superar a desvinculação existente entre o processo de formação e a realidade prática, de maneira a efetivamente atender às necessidades da sociedade, na preparação de recursos humanos, para se atuar na área de saúde.

Buscando soluções, foram realizados seminários nacionais e regionais, encontros, fóruns e debates, promovidos pela ABEN (Associação Brasileira de Enfermagem) e pelo Curso de Enfermagem da UEL. Assim, o período de 1989 a 1990 foi rico em reflexões e análises que objetivaram a superação das muitas dificuldades diagnosticadas na formação do profissional de enfermagem.

Foi promovida, então, a terceira mudança curricular, implantada em 1992. Dentre as alterações mais relevantes, destacam-se a ampliação do curso para quatro anos e a criação do internato de enfermagem no último semestre do curso. A inclusão do internato atendia a uma série de preocupações e permitia a consecução de variados objetivos, quais sejam: "promover a melhoria da qualidade de ensino e assistência de enfermagem, bem como a iniciação científica, criando oportunidades de ensino e aprendizagem que possibilitem a vivência de situações profissionais e o aprofundamento de conhecimentos nas áreas básicas de atuação do enfermeiro"(2).

Contribuindo para essas mudanças curriculares, destaca-se o incentivo do Projeto UNI (uma nova iniciativa para a educação dos profissionais de saúde: União com a Comunidade), implantado em 1991 e financiado pela Fundação W. K. Kellogg, que tem atuado no setor saúde da América Latina, desde 1942, apoiando movimentos e propostas de reforma do ensino. Os princípios do projeto UNI são: "interdisciplinaridade, prática multiprofissional, inserção precoce do aluno na rede de serviços de saúde e na comunidade, ensino centrado no aluno e professor, com papel de orientador da aprendizagem, integração do ensino da área básica com a profissionalizante, ensino e pesquisa orientados pelos problemas prioritários de saúde da população, articulação do ensino, pesquisa e assistência"(1).

Em 1994, o Ministério da Educação e do Desporto, através da Portaria $n^{0} 1721$, de 15 de dezembro de 1994, estabeleceu um novo currículo mínimo para o Curso de Enfermagem e definiu o perfil do enfermeiro generalista, ou seja, com visão não fragmentada de sistemas e especialidades, mas com visão holística e, ainda, com formação para atuar em quatro áreas 
fundamentais: assistência, gerência, ensino e pesquisa.

A proposição dessa portaria obrigou o repensar do Curso de Enfermagem e suscitou a quarta mudança curricular, implementada em 1996.

Para viabilizar essa nova proposta curricular, o Colegiado de Curso promoveu oficinas de trabalho e atividades para aperfeiçoamento didático do corpo docente. Destacam-se, nesse processo de transformação curricular, algumas iniciativas como a criação do NAP (Núcleo de Apoio Pedagógico, implantado em 1994, com a finalidade de proporcionar orientação, assessoria e capacitação pedagógica aos docentes da área de saúde), o projeto PEEPIN (Projeto Especial de Ensino em Assistência Primária à Saúde - Práticas Multiprofissionais e Interdisciplinares, destinado aos alunos do primeiro ano dos cursos do Centro de Ciências da Saúde, desenvolvido através da Metodologia da Problematização, levando grupos de alunos de diferentes cursos a trabalharem em equipe nas Unidades Básicas de Saúde) e o programa PAPP (Programa de Apoio a Projetos de Pesquisa na área de Saúde de Londrina, implantado em 1994, financiando projetos de pesquisa), o que veio diversificar os cenários da aprendizagem para alunos, docentes, profissionais dos serviços e membros da comunidade. Assim, "o processo de concepção do currículo pleno envolveu, em suas etapas iniciais, discussões sobre os princípios, crenças e valores que deveriam nortear a formação do enfermeiro e atender às necessidades do mercado de trabalho, sem perder de vista a capacidade da crítica, reflexão e intervenção sobre ele"(3).

Contudo, tornou-se necessário avaliar esse currículo frente às expectativas do mercado de trabalho, envolvendo, nessa reflexão, os docentes do ciclo básico e do profissionalizante, representantes discentes, profissionais dos serviços de saúde e de associações de classe específicas.

Percebeu-se, no decorrer das oficinas e dos grupos de reflexão, que a predominância do ensino tradicional, a prevalência da formação técnica voltada para ações curativas (visão biologicista), a desarticulação entre teoria e prática, a fragmentação em ciclo básico e clínico, a inadequação de carga horária para algumas disciplinas, a seleção de conteúdos sem parâmetros claros, a preocupação excessiva com a transmissão do conhecimento, em detrimento da qualidade do processo de aprendizagem, a inserção inadequada de algumas disciplinas na grade curricular, a fragilidade na relação com os serviços e o número excessivo de alunos por turmas não preparavam o enfermeiro para a capacidade gerencial com competência para as ações de promoção e prevenção em saúde, exacerbando a dicotomia entre o ensino e a prática.

Diante desse diagnóstico, estabeleceu-se que a meta para o ensino de enfermagem deveria ser "a formação de um profissional consciente de sua responsabilidade histórica, traduzida pela reflexão crítica da sociedade e da prática de assistência à saúde, na perspectiva de redirecionamento dessa prática a partir de seu compromisso com o contexto social e com os reais interesses da comunidade" ${ }^{\prime(4)}$.

Para tentar superar, pelo menos parcialmente, os problemas identificados e permitir a adequada preparação do corpo docente para novas alternativas de ensino, foi desencadeada a quinta mudança curricular, chamada de Currículo de Transição, que vigorou de 1996 a 1999. Esse currículo foi estruturado a partir do eixo saúde-doença, estreitando as relações entre as disciplinas básicas e profissionalizantes, integrando ensino com serviço e buscando alternativas metodológicas que estimulassem a participação ativa do aluno no processo de ensino e aprendizagem.

Paralelamente, o Internato de Enfermagem, planejado e operacionalizado no auge das discussões do currículo de 1996, acabou absorvendo e refletindo em seus objetivos e processo de viabilização das diretrizes, metas, eixos norteadores e perfil expressos na proposta curricular de $1996^{(5)}$.

Assim, o internato é descrito como "uma experiência ímpar no processo de formação dos alunos e na articulação/integração entre as práticas de ensino e de serviço, favorecendo ao aluno uma vivência mais próxima da realidade de trabalho que o espera" ${ }^{\text {"6) }}$.

O Currículo de Transição, avaliado pelo Colegiado do Curso de Enfermagem, três anos após sua implantação, trouxe a adoção de outras estratégias de ensino, como estudos de caso, Metodologia da Problematização, discussão teórica a partir da prática, estudos bibliográficos, visitas domiciliares, visitas aos serviços de saúde, realização de painéis integrados, envolvendo disciplinas do básico e profissionalizante, realização de seminários integrados, elaboração de programa de conteúdos teóricos, com a participação dos alunos em projetos de ensino (Peepin e Papiens - Práticas Multiprofissionais e Interdisciplinares/Programa de Apoio 
a Projetos Integrados de Ensino e Serviço de Saúde, projetos baseados na interdisciplinaridade, no trabalho em equipe multiprofissional, na pesquisa inserida na comunidade e na diversificação dos cenários de aprendizagem, com o objetivo de estimular o desenvolvimento de novos modelos acadêmicos e de assistência à saúde de forma integrada, financiando projetos integrados de ensino e serviços de saúde), de extensão e de pesquisa, diminuindo a distância entre teoria e prática e buscando novos campos de estágio. Mas as mudanças são maiores e acontecem, também, pela promoção e realização de novas formas de avaliação, progressivamente voltadas para a finalidade diagnóstica, que, valendo-se de diferentes instrumentos, foram apontadas pelos alunos como facilitadoras do processo de aprendizagem.

Todavia, tais mudanças aconteceram ainda por iniciativa de algumas disciplinas e não no curso, como um todo.

Em estudos promovidos pelo Colegiado de Enfermagem, em 1998, os alunos solicitaram a aplicação de metodologias que incentivassem a pesquisa e a aprendizagem, de forma ativa, assim como a introdução de mudanças maiores nas estratégias de ensino, para que eles pudessem conhecer a realidade de trabalho do enfermeiro, percebendo melhor as características de seu campo de atuação e as particularidades da atuação em equipe multiprofissional.

Dando continuidade ao processo de discussão e transformação curricular e pautando-se nos princípios da nova Lei de Diretrizes Básicas da Educação Nacional, implantou-se, em janeiro de 2000, o Currículo Integrado, cuja estrutura segue a criação de módulos integrados que viabilizam a interdisciplinaridade e a relação teoria prática, adotando a Metodologia da Problematização, com o objetivo de formar alunos críticos, criativos e ativos, que constroem seus conhecimentos a partir da realidade, e são protagonistas conscientes na construção das transformações desejadas, estando a pesquisa inserida nesse processo.

A nova proposta pedagógica fundamenta-se na certeza de que o aluno é sujeito ativo no processo de construção do seu conhecimento, cumprindo ao professor a condução dos processos de ensino e aprendizagem pelo permanente desafio do raciocínio do aluno e pela progressiva integração de novos conhecimentos às experiências prévias. O conteúdo passa a ser organizado através de sucessivas aproximações e em níveis crescentes de complexidade.

O novo currículo propõe a formação de um profissional capaz de "prestar e gerenciar a assistência de enfermagem com conhecimentos, habilidades e atitudes que poderão influenciar nas decisões políticas e organizacionais na área da saúde" ${ }^{(1)}$, pretendendo, dessa forma, atender às exigências do mercado (com ações assistencias, gerenciais, de pesquisa e educacionais) e acompanhando as mudanças nos contextos social, cultural, político e econômico do país.

\section{O CURRÍCULO INTEGRADO}

Perfil do enfermeiro a ser formado

Com a implementação do Currículo Integrado, o Curso de Enfermagem da Universidade Estadual de Londrina pretende formar profissionais que desempenhem uma prática comprometida com as necessidades de saúde da população, demonstrando, em seu exercício, autonomia, iniciativa, ética, raciocínio investigativo, criatividade, capacidade de comunicação, capacidade de resolução de problemas e de trabalho em equipe interdisciplinar e multiprofissional, valorizando, acima de tudo, o ser humano e a profissão.

Para a formação de um profissional sintonizado com o redirecionamento da política de saúde e com as variações no perfil epidemiológico, fez-se necessária a elaboração e implementação de uma proposta inovadora, que contemplasse não somente a grade curricular, mas que investisse em uma perspectiva pedagógica que permitisse uma ação educativa mais global e crítica.

Fundamentação teórica

A proposta pedagógica que fundamenta o Currículo Integrado articula, dinamicamente, a atuação profissional e o ensino, a prática e a teoria, a academia, o ensino e a comunidade, deixando de centrar-se nas disciplinas e passando a valorizar os processos ou fenômenos importantes para a formação, de maneira integrada, do profissional.

Baseada na concepção crítico-social e respaldada na pedagogia problematizadora, essa proposta veio romper com o ensino tradicional, baseado 
na reprodução de conceitos e noções, tendo o professor como detentor absoluto do saber e marcado pela passividade e falta de atitude crítica do aluno, bem como pela distância entre teoria e prática, condicionantes que trazem para o dia a dia, quer na prática profissional, quer no exercício da cidadania, conseqüências como conformismo, submissão à dominação, individualismo, falta de participação e adoção indiscriminada de modelos de pensamento ${ }^{(7)}$.

Destarte, o processo de ensino deve desenvolver no aluno o seu potencial político-social, juntamente com o seu potencial intelectual, promovendo o pleno desenvolvimento de seus saberes teóricos e práticos para o exercício profissional, formando o indivíduo como sujeito livre e autônomo ${ }^{(8)}$ e fazendo da educação uma responsabilidade social e política ${ }^{(9)}$. Para tanto, faz-se necessário mudar as perspectivas da sala de aula, com a construção de propostas de ensino inovadoras.

Para que a educação possa realmente assumir o seu papel nessa construção, faz-se necessário romper com o saber e o conhecimento autoritários, afastandose do modelo segundo o qual o educador é a figura que centraliza todos os desejos, conhecimentos e possibilidades de ação. A escola precisa cumprir suas finalidades e reinventar-se para, efetivamente, contribuir na formação do futuro profissional, ciente de seus direitos e de suas responsabilidades ${ }^{(10)}$.

No contexto da educação problematizadora, é preciso definir o sujeito do processo pedagógico, quais os objetivos perseguidos no processo educativo (habilidades, atitudes, tipo de profissional/homem/ sociedade que se pretende formar) e como educar (estratégias/metodologia) $)^{(8)}$.

Sob essa nova perspectiva, as experiências anteriores do aluno fornecem elementos importantes para que ele construa seus conhecimentos, assim como se afirma essencial um constante revisitar da realidade de trabalho. Dessa forma, a prática educacional faz-se pelo próprio aluno, de dentro para fora, e não de cima para baixo, como uma doação ou imposição( ${ }^{(11)}$.

Segundo a proposta problematizadora, portanto, o aluno é o centro do processo e o educador é o mediador que vai ajudar a explicitar e a sistematizar aquilo que a vida e o contexto dos educandos fornecem como elementos de análise, reflexão e reestruturação do saber.

Conferindo dinamicidade e organicidade a essa prática pedagógica, temos como elementos constitutivos os componentes: humanos, culturais e metodológicos ${ }^{(12)}$.

Os componentes humanos dizem respeito às relações entre professor e aluno, entre alunos e alunos e entre alunos e comunidade.

Os componentes culturais referem-se às finalidades da educação, pela busca incessante de equilíbrio entre quantidade e qualidade dos conteúdos.

Por fim, os componentes metodológicos abrangem os métodos, as técnicas, os recursos, a organização, a execução e avaliação do processo de ensino e aprendizagem vivenciado e compartilhado por todos que dele participam.

Opção metodológica

A Metodologia da Problematização tem, por momento inicial, a observação da realidade, no decorrer da qual o tema será trabalhado, seguido de reflexão na busca dos possíveis fatores que estão associados ao problema emergente da realidade sob foco.

No segundo momento, definem-se os aspectos que precisam ser conhecidos e compreendidos na busca de respostas para esse problema, assim os pontos-chave, que orientarão os estudos e análises subseqüentes, são determinados.

A seguir, procede-se ao estudo criterioso acerca dos muitos aspectos teóricos relativos aos pontos-chave estabelecidos. É, portanto, no decorrer da teorização, que os alunos desvelam pressupostos e fundamentos que os orientarão na resolução do problema.

O aprofundamento teórico, em confronto com a realidade, possibilita a análise e discussão dos dados colhidos e a proposição de hipóteses de solução, visando intervir naquela parcela da realidade, para a superação dos problemas e dificuldades identificados.

Finalmente, as hipóteses de solução são implementadas, é o momento de aplicação à realidade, caracterizada pela ação concreta teoricamente fundamentada.

Esse método foi denominado Método do Arco de Maguerez e foi proposto objetivando oferecer respaldo ao "educador preocupado com o desenvolvimento de seus alunos e a sua autonomia intelectual, visando pensamento crítico e criativo"(12).

A Metodologia da Problematização permite àqueles que dela participam que cheguem a uma ação prática transformadora, fruto do aprofundamento teórico, 
em confronto com a realidade, em decorrência da elaboração de hipóteses de solução.

Nessa metodologia, a relação dinâmica entre o sujeito que aprende e o objeto do conhecimento verificase por meio de sucessivas aproximações. Dessa forma, o aluno tem possibilidade de aprender a pensar criticamente, desenvolvendo a capacidade de reconhecer a realidade e seus problemas, preparando-se para uma ação transformadora nos contextos profissional e social. Portanto, a Metodologia da Problematização permite ao aluno desenvolver a capacidade de construir seus conhecimentos por meio de situações observadas no contexto real, desencadeando um processo de açãoreflexão-ação, contínuo e progressivo.

Vários autores, como Freire, Libâneo e Saviani, apontam a importância de uma pedagogia problematizadora, afirmando que o aprendizado se dá somente quando o aluno se envolve profundamente com a situação, o que essa metodologia pode permitir, pois o aluno afasta-se de uma prática observada e caminha para uma nova prática, elaborada por ele mesmo, o que gera um envolvimento gradativo do sujeito com o objetivo do conhecimento $^{(13)}$.

Tanto Freire quanto Berbel afirmam ser importante levar os alunos a pensarem sobre a realidade, de maneira crítica, buscando ações capazes de modificála. Para tanto, faz necessário-se observar a realidade, definir o problema, levantar as suas causas e os seus determinantes, teorizar, analisar e chegar a uma nova ação. Desse processo, decorre a transformação criadora, na qual se fundamenta a educação problematizadora. Esse é um processo inacabado, pois permite a todos que dele participam, um contínuo e progressivo desvelamento da realidade.

Pode-se perceber, então, que a Metodologia da Problematização é voltada para a transformação social e processa-se fundamentando-se na certeza de que a educação é uma atividade mediadora entre o indivíduo e a sociedade ${ }^{(7,14)}$.

Na construção do Currículo Integrado do Curso de Enfermagem, da Universidade Estadual de Londrina, foram definidos o papel do professor, enquanto orientador do processo de ensino e aprendizagem, promovendo aprendizagem significativa e estimulando o raciocínio do aluno; o papel do aluno enquanto sujeito ativo no processo de construção do seu próprio conhecimento; bem como as características do conteúdo, ou seja, abordagem por meio de sucessivas aproximações em níveis crescentes de complexidade. Assim sendo, a Pedagogia Problematizadora permite alcançar os objetivos propostos pelo Currículo Integrado, quando possibilita formar profissionais contextualizados "que aprendam, na prática, a transformar alguma parcela da realidade, enquanto se transformam a si mesmos em seu campo de formação acadêmica" ${ }^{(1)}$.

Avaliação

Associada ao projeto pedagógico, a avaliação deve dar dinamicidade ao processo de ensino e aprendizagem, desenvolvendo-se através da interação entre aprendiz e professor, "organizando instrumentos e situações tão diversificados quanto forem necessários, em função das etapas do desenvolvimento do processo" $^{(15)}$.

Para tanto, a avaliação deve realizar-se de modo planejado, a fim de acompanhar o desenvolvimento do educando em todas as suas etapas, diagnosticando, favorecendo a análise do processo e classificando o desenvolvimento do educando, objetivando sempre a formação do perfil profissional que se deseja.

Para atender aos novos preceitos, a avaliação no Currículo Integrado dá-se de forma diagnóstica, formativa e somativa.

A avaliação diagnóstica tem por objetivo "identificar eventuais problemas de aprendizagem e suas possíveis causas, numa tentativa de saná-los"(15), ocorrendo no início do processo para constatar os conhecimentos e habilidades necessários para construção de novas aprendizagens.

"A avaliação formativa, por sua vez, fornece dados para aperfeiçoar o processo ensino e aprendizagem" ${ }^{(15)}$. Portanto, realiza-se ao longo dele e focaliza o desenvolvimento de competências e a formação de habilidades.

Por fim, a avaliação somativa "classifica os resultados de aprendizagem de acordo com os níveis de aproveitamento estabelecidos"(15), procedendo-se no término da unidade na verificação do alcance dos objetivos pré-estabelecidos.

Os processos de avaliação diagnóstica, formativa e somativa efetivar-se-ão pela utilização de diferentes instrumentos que permitam a auto-avaliação, a 
avaliação interpares e outras estratégias (relatórios, provas escritas subjetivas/objetivas, observação sistemática, elaboração de textos/artigos, diferentes formas de pesquisa, entre outras), que possibilitem ao aluno analisar sua progressão na aprendizagem, e, aos professores, replanejarem intervenções oportunas que garantam a superação de problemas e dificuldades diversas.

Portanto, para que a proposta se efetive, é necessário que se avalie o desempenho do aluno em diferentes situações de aprendizagem.

Organização das atividades

O currículo integrado de Enfermagem foi estruturado, portanto, em três séries modulares e uma série de internato, com quatro anos de duração ou 4.192 (quatro mil, cento e noventa e duas) horas, em período integral, ofertando 60 (sessenta) vagas.

As atividades estão distribuídas em teóricas, práticas e ensino clínico. As disciplinas foram integradas em módulos e unidades interdisciplinares. Ao total,são 13 (treze) módulos ${ }^{(1)}$ :

1a SÉRIE:

- Módulo I - A Universidade e o Curso de Enfermagem

- Módulo II - Processo Saúde - Doença

- Módulo III - Processo Saúde - Doença, a partir do Núcleo Familiar

- Módulo IV - Prática Interdisciplinar e Multiprofissional 1

- Módulo V - Avaliação do Estado de Saúde do Indivíduo 2a SÉRIE:

- Módulo VI - Introdução à Saúde do Adulto

- Módulo VII - Prática Interdisciplinar e Multiprofissional

- Módulo VIII - Saúde do Adulto I

- Módulo IX - Organização dos Serviços de Saúde e de Enfermagem

\section{REFERÊNCIAS BIBLIOGRÁFICAS}

1. Universidade Estadual de Londrina (PR). Enfermagem, Colegiado do Curso. Currículo Integrado de Enfermagem da Universidade Estadual de Londrina. Londrina; 1999.

2. Universidade Estadual de Londrina (PR). Enfermagem, Departamento de. Internato de Enfermagem. Londrina; 2000. 3. Hirazawa SA. Uma inovação no ensino de enfermagem na Universidade Estadual de Londrina: integração das disciplinas de saúde do adulto utilizando a metodologia da Problematização. Londrina: UEL; 1998.

4. Takahashi OC. Currículo do Curso de Enfermagem. Londrina: Universidade Estadual de Londrina; 1995. $3^{\text {a }}$ SÉRIE:

- Módulo X - Saúde do Adulto II

- Módulo XI - Prática Interdisciplinar e Multiprofissional 3

- Módulo XII - Da Concepção à Adolescência

$4^{\text {a }}$ SÉRIE:

- Módulo XIII - Internato de Enfermagem

\section{CONCLUSÕES}

A elaboração do novo currículo do Curso de Enfermagem foi um trabalho árduo, que consumiu muitas horas de trabalho de docentes e discentes, comprometidos com a melhoria contínua dos profissionais formados e que ingressam, a cada ano, no mercado de trabalho.

A elaboração foi apenas o primeiro momento de uma longa jornada. O processo de implementação reserva surpresas que precisam ser analisadas, pois sempre - ou quase sempre - o que se mostrou tão consistente, no plano da concepção, expressa falhas e equívocos, quando da consecução.

O compromisso com a formação de enfermeiros mais e mais competentes, mais e mais cônscios das responsabilidades inerentes ao seu fazer, exige dos encarregados de sua formação o acompanhamento constante dos limites e possibilidades postos pelo contexto acadêmico/profissional.

Assim, acompanhar e analisar o processo de implementação do Currículo Integrado do Curso de Enfermagem é fundamental; determinar os fatores que vêm atuando enquanto dificultadores é essencial, bem como, reconhecer os aspectos facilitadores é de suma importância, pois, somente com base nos dados evidenciados, é possível garantir a superação das dificuldades, na edificação de uma prática pedagógica consistente, com o perfil do profissional a ser formado.

5. Souza NA. A avaliação da aprendizagem na construção do saber e do fazer docente. [tese]. Marília (SP): Faculdade de Filosofia e Ciências/UNESP; 1999.

6. Vannuchi MTO, Baduy RS, Gil CRR, Nunes EFPA, Lima JVC. O Internato do Curso de Enfermagem da UEL: relato de uma experiência. Divulgação em Saúde para Debate. 1996 nov; (15):23-5.

7. Bordenave JD. Alguns fatores pedagógicos. Revista Interamericana de Educação de Adultos. 1983; 2(1-2):11-8.

8. Fleuri RM. Educar para quê? 9a ed. São Paulo: Cortez; 1997. 9. Freire P. Educação como prática da liberdade. 3. ed. Rio de Janeiro: Paz e Terra; 1971.

10. Grossi EP. Construtivismo pós-piagetiano. Um novo paradigma sobre aprendizagem. $4^{a}$ ed. Rio de Janeiro: Vozes; 1993. 
11. Freire P. A Pedagogia do oprimido. $13^{a}$ ed. São Paulo: Paz e Terra; 1983.

12. Berbel NAN. Questões de ensino. Notícia 1996; (3):1-3.

13. Berbel NAN. Metodologia da problematização: fundamentos a aplicações. Londrina: UEL; 1999.

14. Saviani D. Educação: do senso comum à consciência filosófica. $12^{\mathrm{a}}$ ed. São Paulo: Cortez; 1996.

15. Marcondes MAS. Avaliação da aprendizagem. Londrina: Cortez; 2000. 